\title{
Novel technique of endoscopic full-thickness resection for superficial nonampullary duodenal neoplasms to avoid intraperitoneal tumor dissemination
}

Authors

Institutions
Ken Ohata ${ }^{1}$, Kouichi Nonaka ${ }^{1}$, Eiji Sakai ${ }^{1}$, Yohei Minato ${ }^{1}$, Hitoshi Satodate ${ }^{2}$, Kazuteru Watanabe ${ }^{2}$, Nobuyuki Matsuhashi ${ }^{1}$

${ }^{1}$ Department of Gastroenterology, NTT Medical Center Tokyo, Tokyo, Japan

2 Department of Surgery, NTT Medical Center Tokyo, Tokyo, Japan submitted

7. January 2016

accepted after revision

25. April 2016

\section{Bibliography}

DOI http://dx.doi.org/

10.1055/s-0042-107666

Published online: 29.6.2016

Endoscopy International Open

2016; 04: E784-E787

(c) Georg Thieme Verlag KG

Stuttgart · New York

E-ISSN 2196-9736

\section{Corresponding author}

\section{Ken Ohata, MD}

Division of Gastroenterology NTT Medical Center Tokyo 5-9-22 Higashi-gotanda, Shinagawa-ku, Tokyo, 141-8625 Japan

Fax: +81-3-3448-6541

ken.ohata1974@gmail.com
Background and study aims: Recently, laparoscopic and/or endoscopic full-thickness resection (FTR) has been reported to be a useful technique for the treatment of superficial duodenal neoplasms (SDNs). In the current study, we evaluated clinical outcomes in 5 consecutive patients who underwent resection of nonampullary SDNs using laparoscopy-assisted endoscopic full-thickness resection with ligation Device (LAEFTR-L), which is an alternative FTR method developed to avoid peritoneal dissemination. Using a snare technique with a ligation band, the duodenal lesions were easily resected. The provisional and

\section{Introduction}

$\nabla$

The therapeutic strategy for superficial duodenal neoplasms (SDNs) remains unestablished. Although endoscopic resection can be a curative procedure for such lesions [1], it still remains technically challenging because of the high risk of severe adverse events (SAEs) including delayed perforation [2]. On the other hand, surgical treatment of such lesions often results in extensive resections, causing significant morbidity. Recently, laparoscopic and/or endoscopic full-thickness resection (FTR) has been reported to be a useful technique for the treatment of nonampullary SDNs [3-5]. Despite their minimally invasive nature, all FTR procedures are associated with the possibility of intraperitoneal tumor dissemination. Therefore, we developed an alternative FTR method, which we call laparoscopy-assisted endoscopic full-thickness resection with ligation device (LAEFTR-L). Herein we report on resection of nonampullary SDNs using LAEFTR-L in 5 consecutive patients and an evaluation of the efficacy and safety of these procedures. additional sutures for the resected site prevented delayed perforation and bleeding and they also protected the abdominal cavity from direct exposure to malignant cells. Complete resection could be achieved and FTR was histologically confirmed in all cases. The mean operation time was 173 minutes (range 138-217 minutes). Mean diameter of the resected specimen was $24 \mathrm{~mm}$ (range $18-32 \mathrm{~mm}$ ). No adverse events (AEs) were observed. LAEFTR-L, which can achieve complete resection of nonampullary SDNs without severe AEs and peritoneal dissemination, could be a useful technique for the treatment of such lesions.

\section{Case reports \\ $\nabla$}

\section{Patients}

From June 2015 to September 2015, 5 patients underwent resection of nonampullary SDNs using LAEFTR-L. Written informed consent was obtained from each patient. This study was approved by the ethics committee of the NTT Medical Center.

\section{LAEFTR-L procedure}

The LAEFTR-L procedure was performed under general anesthesia. The set up for the LAEFTR-L procedure was previously described [3]. After mobilizing the duodenum from the retroperitoneum, a forward-viewing endoscope (GIF260J; Olympus, Medical Systems Corp., Tokyo, Japan) was inserted into the duodenum and the target lesion was identified ( $\bullet$ Fig. 1a). Endoscopic light was used to help the surgeon identify the tumor location. Using an endoclip as a marker, the tumor (including the seromuscular layer) was ligated using a ligation device (PNEUMO-ACTIVATE EVL DEVICE; Sumitomo Bakelite Corp., Ltd. Tokyo, Japan) ( $\bullet$ Fig. 1b). The laparoscopist then temporarily sutured the seromuscular layer, after confirming the presence of a full-thickness aspirated sign

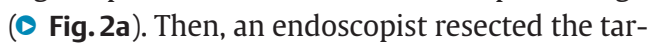



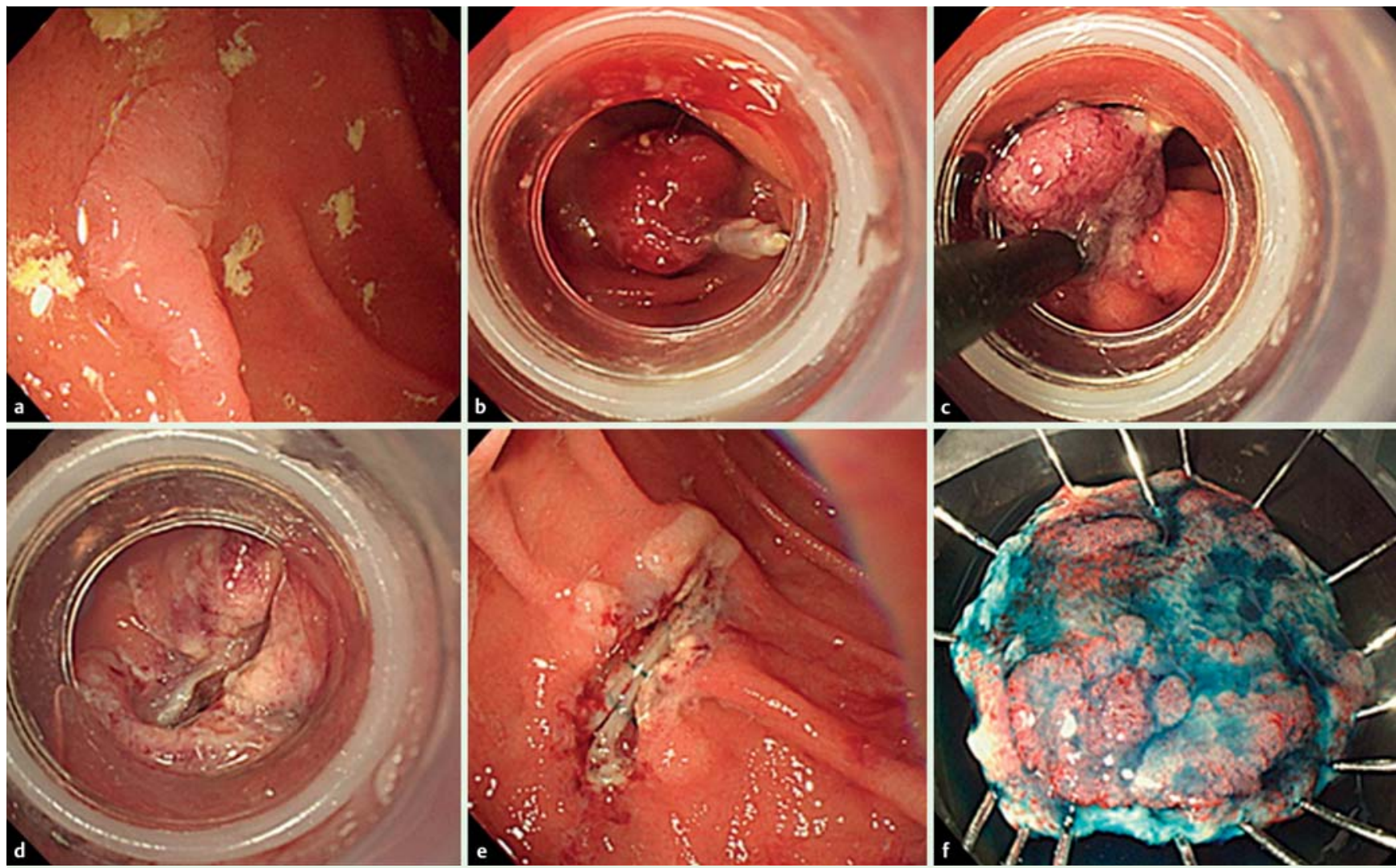

Fig. 1 Endoscopic findings of laparoscopy-assisted endoscopic full-thickness resection with ligation device for superficial duodenal neoplasm. a A flat elevated lesion, measuring $15 \mathrm{~mm}$ in diameter, located at the opposite side of the ampulla of Vater. b Using an endoclip as a marker, the targeted lesion was ligated with a ligation device. $\mathbf{c}$ The tissue including the target lesion was resected with a snare technique. $\mathbf{d}$ Resection site. e Laparoscopic temporary suture secures patency of the duodenal wall. $\mathbf{f}$ Resected lesion after administration of $0.1 \%$ indigo carmine solution.

geted lesion under the ligation band using snare technique ( $\bullet$ Fig.1c, $\bullet$ Fig.1d, $\bullet$ Fig.1e). Consequently, the presutured site was reinforced laparoscopically ( $\bullet$ Fig. 2b). Finally, the specimen

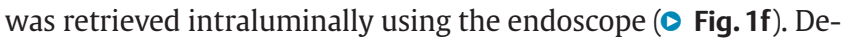
spite the lack of a seromuscular layer, the provisional and additional sutures prevented exposure of the abdominal cavity to malignant cells. In addition, vessels were ligated during the closure of the defect in the duodenal wall. Therefore, the LAEFTR-L procedure was completed in a closed manner without complications.

Inhibitors of gastric acid and protease secretion were administered to the patients during their hospitalizations. A normal diet was resumed approximately 2 days after the procedure, and the patients were discharged after a 1-week hospital stay.

\section{Clinical outcomes \\ $\nabla$}

All lesions were successfully resected with the LAEFTR-L procedure. Clinicopathological characteristics are shown in $\bullet$ Table 1. Two of the 5 tumors were located at the duodenal bulb, and the others at the second part of the duodenum (opposite to the ampulla of Vater). The mean operative time was 173 minutes (range 138-217 minutes). Mean diameter of the resected specimen was $24 \mathrm{~mm}$ (range $18-32 \mathrm{~mm}$ ), and the mean tumor size was $9 \mathrm{~mm}$ (range 7-11 mm). Complete resection was achieved, and fullthickness resection was histologically confirmed in all cases ( $\bullet$ Fig.3). Two of the 5 lesions were intramucosal carcinoma. No

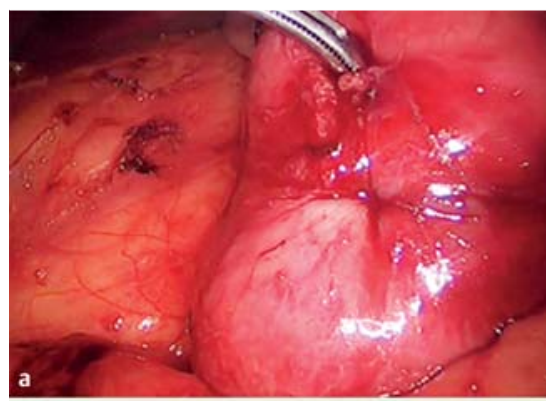

Fig. 2 Laparoscopic findings of laparoscopyassisted endoscopic full-thickness resection with ligation device for superficial duodenal neoplasm. a Full-thickness aspirated sign, which helps the surgeon accurately identify the tumor

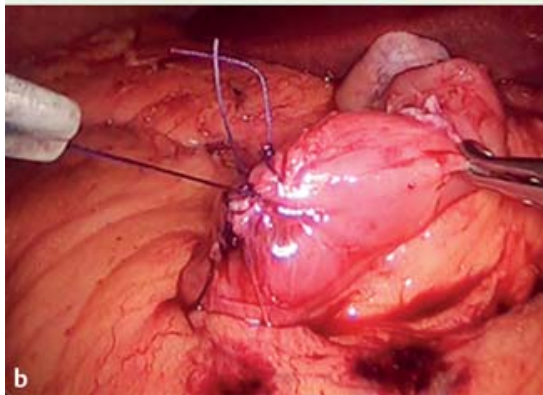
location. b The presutured site was reinforced to prevent delayed perforation and/or bleeding.

AEs were observed. Importantly, all the procedures were completed without the tumors contacting the peritoneum. 


\begin{tabular}{|c|c|c|c|c|c|c|c|c|c|c|c|}
\hline Case & Age & Sex & Location & $\begin{array}{l}\text { Total operative } \\
\text { (endoscopic resec- } \\
\text { tion) time (min) }\end{array}$ & $\begin{array}{l}\text { Size of } \\
\text { resected } \\
\text { specimen } \\
(\mathrm{mm})\end{array}$ & $\begin{array}{l}\text { Tumor } \\
\text { size } \\
(\mathrm{mm})\end{array}$ & $\begin{array}{l}\text { Macro- } \\
\text { scopic clas- } \\
\text { sification }\end{array}$ & $\begin{array}{l}\text { Patholo- } \\
\text { gical } \\
\text { diagnosis }\end{array}$ & $\begin{array}{l}\text { R0 re- } \\
\text { section }\end{array}$ & $\begin{array}{l}\text { Hospital } \\
\text { stay, day }\end{array}$ & $\begin{array}{l}\text { Adverse } \\
\text { events }\end{array}$ \\
\hline 1 & 60 & $\mathrm{M}$ & $\begin{array}{l}\text { Second part of } \\
\text { duodenum } \\
\text { Opposite the } \\
\text { papilla of Vater }\end{array}$ & $180(5)$ & 20 & 9 & depressed & Cancer & Yes & 8 & None \\
\hline 2 & 50 & $\mathrm{~F}$ & $\begin{array}{l}\text { Second part of } \\
\text { duodenum } \\
\text { Opposite the } \\
\text { papilla of Vater }\end{array}$ & $143(4)$ & 18 & 11 & Depressed & Adenoma & Yes & 7 & None \\
\hline 3 & 52 & M & $\begin{array}{l}\text { Third part of } \\
\text { duodenum } \\
\text { Anterior wall }\end{array}$ & $187(4)$ & 26 & 7 & $\begin{array}{l}\text { Flat- } \\
\text { elevated }\end{array}$ & Adenoma & Yes & 6 & None \\
\hline 4 & 65 & M & $\begin{array}{l}\text { Second part of } \\
\text { duodenum } \\
\text { Opposite the } \\
\text { papilla of Vater }\end{array}$ & $138(3)$ & 32 & 7 & Depressed & Adenoma & Yes & 8 & None \\
\hline 5 & 68 & M & $\begin{array}{l}\text { Duodenal bulb, } \\
\text { Posterior wall }\end{array}$ & $217(5)$ & 24 & 11 & $\begin{array}{l}\text { Flat- } \\
\text { elevated }\end{array}$ & Cancer & Yes & 7 & None \\
\hline
\end{tabular}
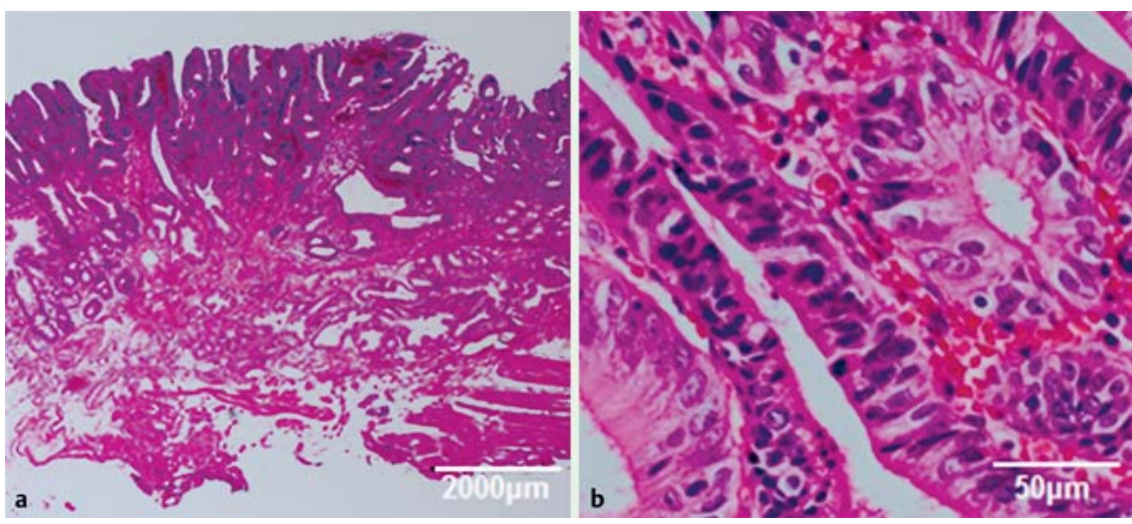

Fig. 3 Pathological findings. HE staining of resected specimen (Case 1). Intraepithelial adenocarcinoma was completely resected with the muscular layer. a Low magnification. b High magnification.

\section{Discussion}

$\nabla$

Because the malignant potential of SDN is difficult to define from the preoperative endoscopic diagnosis [6], complete en-bloc resection is necessary to achieve appropriate pathological evaluation and treatment. Although conventional endoscopic mucosal resection (EMR) could be a curative strategy for SDNs, complete resection is challenging, especially for flat or non-lifting lesions. In recent years, the indications for ESD have been expanded to SDNs [7]. However, delayed perforation in the duodenum, in particular, may cause potentially fatal peritonitis or retroperitoneal complications, requiring emergency open surgery to counter leakage of bile and pancreatic juices [8]. Moreover the technical difficulty of this procedure is extremely high, due to the poor maneuverability of the endoscope and the thin wall. Therefore, duodenal ESD is not a standard clinical procedure. On the other hand, laparoscopic FTR procedures reportedly achieve higher complete resection rates without SAEs [3,4]. Although shortterm clinical outcomes were preferable, we need to consider the risk of intraperitoneal tumor dissemination, given the lack of data on long-term outcomes in patients undergoing conventional FTR procedures.
Compared with conventional FTR procedures, LAEFTR-L has two advantages. Most importantly, the resected specimen can be collected intraluminally, avoiding contact with the peritoneum. Shen et al. conducted an animal model study and revealed that pneumoperitoneum from laparoscopic surgery could be a risk factor for peritoneal dissemination of tumor cells [9]. Because long-term outcomes of SDNs treated with the conventional FTR method rarely have been investigated, peritoneal exposure of tumor cells should be avoided as far as possible. Moreover, LAEFTRL does not require proficient experience in ESD. The simplicity of this procedure enables endoscopists to resect target lesions easily. Indeed, total operative time was not different from previous reports on conventional FTR for SDNs $[3,4]$, and endoscopic resection time was even significantly shorter.

Tumor size is a major limiting factor when considering the indication for LAEFTR. In the current study, mean specimen size was $24 \mathrm{~mm}$. Lee et al. reported that esophageal subepithelial lesions no larger than $13 \mathrm{~mm}$ could be successfully resected by EMR with a ligation device [10]. Considering the size of the ligation device, lesions smaller than $15 \mathrm{~mm}$ in diameter may be candidates for this procedure. Although additional studies are needed, application of a large oblique cap may enable en-bloc resection of larger lesions. In addition, tumor location is also important to deci- 
sions about the indication for LAEFTR-L. LAEFTR-L cannot to be applied to lesions close to the ampulla of Vater, because mobilization of these portions is technically difficult with laparoscopic procedures.

In conclusion, LAEFTR-L may be a promising technique for the treatment of nonampullary SDNs which can achieve complete resection without peritoneal exposure of tumor cells or SAEs. Prospective studies are needed to further evaluate the efficacy and safety of LAEFTR-L procedures.

\section{Competing interests: None}

\section{References}

1 Poultsides GA, Huang LC, Cameron JL et al. Duodenal adenocarcinoma: clinicopathologic analysis and implications for treatment. Ann Surg Oncol 2012; 19: $1928-1935$

2 Yamamoto Y, Yoshizawa N, Tomida $H$ et al. Therapeutic outcomes of endoscopic resection for superficial non-ampullary duodenal tumor. Dig Endosc 2014; 26: 50-56

3 Ohata K, Murakami M, Yamazaki Ket al. Feasibility of endoscopy-assisted laparoscopic full-thickness resection for superficial duodenal neoplasms. Sci World J 2014; 16: 239627
4 Sakon M, Takata M, Seki H et al. A novel combined laparoscopic-endoscopic cooperative approach for duodenal lesions. J Laparoendosc Adv Surg Tech A 2010; 20: 555-558

5 Abe N, Takeuchi H, Shibuya $M$ et al. Successful treatment of duodenal carcinoid tumor by laparoscopy-assisted endoscopic full-thickness resection with lymphadenectomy. Asian J Endosc Surg 2012; 5: 81 - 85

6 Goda K, Kikuchi D, Yamamoto Y et al. Endoscopic diagnosis of superficial non-ampullary duodenal epithelial tumors in Japan: Multicenter case series. Dig Endosc 2014; 26: 23 - 29

7 Hoteya S, Yahagi N, Iizuka T et al. Endoscopic submucosal dissection for nonampullary large superficial adenocarcinoma/adenoma of the duodenum: feasibility and long-term outcomes. Endosc Int Open 2013; 1: $2-7$

8 Inoue T, Uedo N, Yamashina T et al. Delayed perforation: a hazardous complication of endoscopic resection for non-ampullary duodenal neoplasm. Dig Endosc 2014; 26: 220-227

9 Shen MY, Huang IP, Chen WS et al. Influence of pneumoperitoneum on tumor growth and pattern of intra-abdominal tumor spreading: in vivo study of a murine model. Hepatogastroenterology 2008; 55: 947-951

10 Lee DG, Kim GH, Park DY et al. Endoscopic submucosal resection of esophageal subepithelial lesions using band ligation. Endoscopy 2011; 43: $822-825$ 